\title{
A Formação de Professores das Séries Iniciais e sua Relação com o Ensino e Aprendizagem: Uma Revisão em Periódicos Brasileiros
}

Luiza Renata Felix de Carvalho Lima

Maria Elvira do Rego Barros Bello

Maxwell Roger da P. Siqueira

\begin{abstract}
Resumo
Neste trabalho são apresentados dados de um estudo exploratório que analisou a produção acadêmica presente em seis periódicos brasileiros, referente à Formação de Professores de Ciências voltadas para as Séries Iniciais do Ensino Fundamental I, no período entre 2004 a 2013. O objetivo foi avaliar como essa formação tem sido difundida e abordada nas Séries Inicias, e verificar sua relevância nas pesquisas acadêmicas publicadas nos periódicos analisados, nos últimos 10 anos. A partir dos títulos, resumos e metodologias analisadas, foi possível verificar a modalidade de Ensino para a qual a formação estava sendo direcionada e as características metodológicas particulares de cada grupo formador. Dessa forma, dentre os seis periódicos analisados, foi encontrado um total de 1583 artigos, dos quais apenas 11 foram direcionados para a Formação de Professores nas Séries Iniciais, dentre esse total, quatro foram analisados e suas principais características foram descritas.
\end{abstract}

Palavras-chave: Ensino de Ciências, formação de professores, Séries Iniciais.

\section{Abstract \\ Teacher education training series and its relation to teaching and learning: a review on brazilian journals}

This study presents an exploratory study that examined the academic production present in six Brazilian journals related to Teacher Education Sciences focused on the early grades of elementary school I, between 2004 to 2013 are presented The objective was to evaluate how this training widespread and has been addressed in the initial grades, and verify its relevance in academic research published in the journals analyzed in the last 10 years. From the titles, abstracts and methodologies analyzed, it was possible to verify the mode of education for which the training was being targeted and the particular methodological characteristics of each group forming. Thus, among the six newspapers analyzed, we found a total of 1583 articles, of which only 11 were allocated to the Training of Teachers in the early grades, of this total, four were analyzed and their main characteristics were described.

Keywords: science education, teacher training, early grades.

DOI: Em andamento. 


\section{Introdução}

A produção científica acadêmica no Brasil tem expandido significativamente, chega a ser comparável com à dos países mais avançados (SCHWARTZMAN, 2008). Diversos estudos apontam essa propagação, por exemplo, Fracalanza (1992), Megid Neto (1999), Lemgruber (1999); Slongo (2004) e Teixeira e Megid Neto (2005). Aliado a essa demanda, crescem também os eventos nacionais e internacionais, periódicos que tem como objetivo disseminar os resultados das pesquisas nas áreas de Química, Física e Biologia. Desde o final da década de 1960, essa produção tem tomado significativas proporções, de modo a, direta ou indiretamente, subsidiar o Ensino de Ciências (EC) no país (FERNANDES; MEGID NETO, 2011). Por meio de trabalhos do tipo estado da arte, que se destacam por possuir caráter bibliográfico e por mapear e discutir certa produção acadêmica em diferentes campos do conhecimento, a fim de verificar quais aspectos e dimensões vem sendo evidenciados nos trabalhos (FERREIRA, 2002), é possível observar que o EC nas Séries Iniciais (SI) não se evidencia nas pesquisas voltadas para essa área, no Brasil. De acordo com as investigações de Moreira (2004), Francisco e Queiroz (2008) e Teixeira e Megid Neto (2012) é possível verificar essa discrepância direcionada a essa modalidade de ensino, sendo ainda considerada uma lacuna que deve ser preenchida por pesquisas futuras.

Levando em consideração a importância do Ensino de Ciências nas Séries Iniciais no processo de formação psico-sócio-cognitiva do indivíduo, a presente pesquisa identificou e analisou, por meio da pesquisa bibliográfica, os artigos publicados em seis periódicos brasileiros. Buscou-se a partir dos temas e resumos dos trabalhos, observar a frequência das pesquisas destinadas à Formação de Professores (FP) nas Séries Iniciais e identificar dentre essas, as Instituições de Ensino Superior que se destacam entre as pesquisas e as características desses grupos de formação.

\section{O Ensino de Ciências nas Séries Iniciais}

Aprender Ciências é aprender a ler a realidade e o mundo, de forma que essa leitura contribua para a formação integral do aluno, reconhecendo a si mesmo como protagonista da realidade em que vive e atuando de forma ativa na tomada de decisões que permeiam a sociedade em que está inserido (FAGUNDES; LIMA, 2009). Partindo desse pressuposto, vemos a necessidade de proporcionar um Ensino de Ciências que seja capaz de emergir desde as Séries Iniciais, promovendo concepções e conceitos básicos da Ciência aos alunos, que venham a evoluir e se concretizar com o desenvolvimento do aluno no processo de ensino. Os Parâmetros Curriculares Nacionais (PCN) de Ciências da Natureza estabelecem como traços gerais para o desenvolvimento do EC no EF a promoção de um ensino capaz de influenciar a desenvoltura da autonomia nos alunos a fim de que estes se apropriem do conhecimento e sejam capazes de participar desde cedo da sociedade que convive com a expansão e a supervalorização do conhecimento científico. Quando o EC estimula o aluno a desenvolver habilidades como pensar 
sobre um determinado assunto, elaborar, testar e comprovar hipóteses, este, implicitamente, contribui para que esse aluno se torne agente da construção de seu conhecimento (LIMA, 2001).

Para a promoção de um EC que possibilite ao professor das SI habilidades para atuar numa perspectiva interdisciplinar, como sugere os PCN para o Ensino Fundamental (VIECHENESKI; CARLETO, 2011), seria necessário uma reestruturação nos cursos de Formação Inicial (FI) que diplomam esses profissionais. Diversos pesquisadores tecem críticas a essa formação, conhecida como Licenciatura em Pedagogia, que são considerados polivalentes (DUCATTI-SILVA, 2005). Entretanto, não subsidiam aos professores a atuarem da mesma forma, apresentando diversas restrições conteúdistas (NONO; MIZUKAMI, 2006).

No Brasil, os cursos de Licenciatura em Pedagogia geralmente possuem uma disciplina relacionada à Metodologia das Ciências, sendo essa responsável por abordar toda a parte conceitual e metodológica que os futuros professores utilizarão para embasar suas aulas. Dessa forma, há tempos pesquisadores debatem sobre a formação desses professores que atuarão nessa modalidade de ensino, na problemática de estabelecer se essa formação está relacionada ao "saber Ciências" e ao "saber ensinar Ciências" (ROCHA, MEGID NETO, 2009).

Segundo Lima e Maués (2006), a maioria dos professores que leciona Ciências nas SI não possui segurança, tão pouco convicção da necessidade de se aprender Ciências. Essas aulas acontecem de forma descontextualizada, onde o uso do livro didático, vídeos e questionários, são estratégias que se destacam nas metodologias adotadas por estes professores. A evidência em temas como saúde, alimentação e higiene, também são frequentes nas aulas de Ciências, em detrimento de conteúdos mais voltados à área, devido à falta de domínio dos professores ao mediarem esse tipo de conhecimento (SILVA, 2003). Assim, pode-se verificar a necessidade desses professores atuarem em grupos de Formação Continuada (FC), que possibilitem e estimulem a reflexão da sua própria prática.

\section{A Importância da Formação Continuada}

De acordo com Viecheneski e Carleto (2011), os PCN para o EF orientam que há uma necessidade do EC ser desenvolvido numa perspectiva interdisciplinar, sendo o professor responsável por mediar e elaborar estratégias que possam contribuir como forma de ampliação e compreensão dos conceitos científicos, estando estas vinculadas à situações do contexto social em que os alunos estão inseridos. Entretanto, a Fl direcionada a esses professores não oferecem os subsídios necessários para que os professores desenvolvam essas capacidades, possibilitando que estes se refugiem em suas disciplinas.

Também é fundamental estabelecer que a Formação de Professores não se esgota no curso de graduação, pois deve ser considerada um processo contínuo, construído e desenvolvido no contexto escolar. Nesse sentido, Schnezler (1996) estabelece três razões que justificam a

DOI: Em andamento. 
formação continuada de professores: a primeira é a necessidade de contínuo aprimoramento profissional e de reflexões críticas sobre a própria prática pedagógica; segunda é a necessidade de se superar o distanciamento entre contribuições da pesquisa educacional e por fim, a visão simplista que os professores enxergam de sua própria prática docente. Contudo, como destaca Fourez (2003), a formação dos licenciados está mais centrada sobre o projeto de fazer deles técnicos de Ciências do que de fazê-los educadores, não atribuindo aos professores possibilidades para atuarem como mediadores do conhecimento.

Segundo Freitas e Villani (2002), é necessário uma ação orientadora dos especialistas, pois existe muita resistência entre os professores da Educação Básica às mudanças, por estes possuírem crenças, valores e teorias implícitas que permeiam sua prática docente e compõem sua identidade profissional. A necessidade de estabilidade, muitas vezes, impedem a atuação desses professores em grupos de formação continuada.

A identidade profissional do professor está em constante transformação. Para Pimenta e Anastasiou (2002, p.77):

"[...] uma identidade profissional se constrói, pois, com base na significação social da profissão; na revisão constante dos significados sociais da profissão; na revisão das tradições. Mas também com base na reafirmação de práticas consagradas culturalmente que permanecem significativas. [...] Constrói-se, também, pelo significado que cada professor, enquanto ator e autor, confere à atividade docente em seu cotidiano, em seu modo de situar-se no mundo, em sua história de vida, em suas representações, em seus saberes, em suas angústias e anseios, no sentido que tem em sua vida o ser professor."

Nessa mesma perspectiva, Pérez e Aguado (2003) evidenciam a consciência que os professores têm de determinadas informações, estratégias e atividades, que, no entanto, se mostram inseguros em relação a suas eficácias. Dessa forma, suas concepções absolutistas do conhecimento e suas próprias rotinas e crenças, se convertem como obstáculos que não contribuem para a mudança de postura.

Muitos autores defendem que a formação continuada se faz necessária para suprir as limitações e problemas oriundos da FI, que perpetuam no trabalho docente (KRASILCHIK,1987) Por outro lado, alguns defendem a importância da FC como consequência da dinamicidade das informações, conhecimento e processo de Ensino e Aprendizagem, sendo assim, enfatizam a importância dos professores se manterem atualizados e em formação (MENEZES,1996). Além dessas perspectivas, há os que defendem a FC como um processo ininterrupto, não como um instrumento destinado a suprir deficiências da Fl, nem como algo eventual, mas sim como parte integrante do exercício, que deve acompanhar toda a trajetória profissional do professor (AMARAL,2004) . 
No Brasil, os cursos de FP tanto os voltados para a sua preparação, quanto os voltados para a sua atualização, vêm sendo considerados insatisfatórios (GARRIDO; CARVALHO, 1995). Segundo os PCN (BRASIL, 2006, p.3):

"A atual política parte dos seguintes princípios: a formação do educador deve ser permanente e não apenas pontual; formação continuada não é correção de um curso por ventura precário, mas necessária reflexão permanente do professor; a formação deve articular a prática docente com a formação inicial e a produção acadêmica desenvolvidas nas Universidades; a formação deve ser realizada também no cotidiano da escola em horários específicos para isso, $e$ contar pontos na carreira dos professores."

A não integração da Universidade com as Escolas de Ensino Fundamental e Médio e entre os estudos teóricos e a prática docente têm sido apontados por pesquisadores em Educação em Ciência, no mundo todo, como algumas das causas, entre outras, desta ineficiência. A escola deve ser concebida como lugar de produção de conhecimento pedagógico, onde as práticas adotadas pelos professores de ciências sejam consideradas em grupos de $\mathrm{FC}$, como saberes válidos e particulares de cada professor (CARVALHO; GIL-PÉREZ, 1993).

Dessa forma, Veiga e Viana (2012), propõem alguns critérios para a estruturação de uma formação que transcende o ensino que pretende ser uma mera atualização científica e pedagógica, onde o professor é considerado "instrumento de reprodução social", são eles: a escola que questiona seu papel social e a sua responsabilidade quanto aos problemas educativos; o desenvolvimento de professores em torno do desenvolvimento do contexto em que estão inseridos e nas diversidades presentes no seu dia a dia escolar; o estímulo indagação e criticidade em sua própria prática pedagógica; a interpretação da diversidade como um recurso acerca da ótica da pesquisa e da intervenção e o questionamento e recriação de conteúdos curriculares, estratégias de ensino, materiais didáticos e avaliação, de forma que sejam ajustados às características dos alunos.

Considerando esse contexto, se faz necessário que os professores façam parte de grupos de FC que possibilitem os mesmos a refletirem sobre sua didática e sobre suas ações em sala de aula, como promoção de um ensino capaz de possibilitar a formação de cidadão críticos e comprometidos com a sociedade. Além disso, para possibilitar a atuação desses professores nas SI como profissionais capacitados que possam compreender que a concepção de professores reflexivos se faz na ação (SCHON, 1992).

\section{Processo Metodológico}

Buscando realizar uma revisão bibliográfica sobre as pesquisas que tem como foco a formação dos professores de Ciências das Séries Iniciais, procuramos identificar e descrever os

DOI: Em andamento. 
artigos publicados em periódicos científicos nacionais nos últimos dez anos (2004 - 2013). Ou seja, verificar e discutir as características e tendências gerais dos artigos, as metodologias adotadas no estudo e a produção acadêmica na área, analisando o período mais contemporâneo, os últimos 10 anos. Como critério de seleção, optou-se por periódicos que abordam o ensino de Ciências e possuem versão online, de forma que facilite o acesso aos exemplares. 0 critério utilizado para busca foi o de palavras chaves no título e resumos dos artigos, por vezes, até nas metodologias.

Dessa forma, os periódicos consultados foram:

- Revista Ciência \& Educação (C \& E): volume 15 - 2004 ao volume 19 - 2013;

- Revista Investigação em Ensino de ciências (IENCI): volume 14 - 2004 ao volume 18 - 2013;

- Revista Brasileira de Pesquisa em Educação em Ciências (RBPEC): volume 9 - 2004 ao volume 13 -2013 ;

- Revista Experiências em Ensino de Ciências (EENCI): volume 4 - 2004 ao volume 8 - 2013;

- Revista Electrónica de Enseñanza de las Ciencias (REEC): volume 7 - 2004 ao volume 12 - 2013;

- Revista de Educação, Ciência e Tecnologia (Alexandria): volume 2 - 2004 ao volume 7- 2013;

Todos os periódicos analisados encontram-se disponíveis em versão eletrônica no próprio site da revista.

\section{Análise dos Periódicos}

A partir da busca realizada nos seis periódicos anteriormente descritos, sobre a FP nas SI no período destacado, foi possível observar que não foi encontrado nenhum artigo que discute essa temática na Revista de Educação, Ciência e Tecnologia (Alexandria), sendo identificado apenas um total de onze artigos nos seis periódicos analisados, o título e autoria dos artigos são:

- Revista Ciência \& Educação:

1. Ensino de Ciências no Fundamental 1: Perfil de um grupo de professores em Formação Continuada num contexto de Alfabetização Científica. Rogério Gonçalves Nigro e Maria Nizete Azevedo. V.17, n.3, 2011.

2. Construção de práticas didático-pedagógicas com orientação CTS: impacto de um programa de formação continuada de professores de ciências do ensino básico. Celina Terneiro Vieira e Rui Marques Vieira. V.11, n.2, 2005.

3. Troca entre universidade e escola na formação docente: uma experiência de formação inicial e continuada. Nora Ney Santos Barcelos e Alberto Villani. V.12, n.1, 2006.

- Revista Investigação em Ensino de Ciências:

6 DOI: Em andamento.

R. Bras. de Ensino de C\&T 
4. O Conhecimento Físico na Formação de Professores do Ensino Fundamental I. Lenir Abreu, Nelson Bejarano e Dielson Hohenfeld. V1, n.1, 2013.

5. Conhecimento do Conteúdo Científico e a Formação do Professor das Séries Iniciais do Ensino Fundamental. Marcos Daniel Longhini. V.13, n.1, 2008.

6. O Ensino de Física nas Séries Iniciais do Ensino Fundamental: Um estudo das influências das experiências docentes em sua prática em sala de aula. MONTEIRO, M.A.A.; TEIXEIRA, O.P.B. V.9, n.1, 2004.

- Revista Experiências em Ensino de Ciências:

7. Formação Continuada de professores das Séries Iniciais na Modalidade semi-presencial: aprendendo Ciências com atividades Mãos-na-massa. Carlos Schroeder, Eliane Angela Veit e Marta Feijó Barroso. V. 62011.

8. A Formação de Futuros Professores dos Anos Iniciais do Ensino Fundamental: uma discussão a partir de uma atividade de ensino de geometria. Simone Pozebon, Anemari Roesler Luersen Vieira Lopes, Laura Pippi Fraga e Jucilene Hundertmarck. V.8, n.3, 2008.

- Revista Brasileira de Pesquisa em Educação em Ciências:

9. Formação Inicial e Continuada de Professores Num Núcleo de Pesquisa em Ensino de Ciências. Agustina Rosa Echeverría e Celso Martins Belisário. V. 8 N. 3, 2008.

10. Las concepciones y creencias de profesores de ciencias naturales sobre ciencia, su enseñanza y aprendizaje, mediadas por la formación inicial, la educación continuada y la experiencia profesional. Esteban Alberto Rodríguez Garrido e Jesús Angel Meneses Villagrá. V. 5, n. 2, 2005.

- Revista Electrónica de Enseñanza de las Ciencias:

11. Programa de formação de educadoras de infância: Seu contributo para a (re)construção de concepções Ciência-Tecnologia-Sociedade. Maria José Rodrigues e Rui Marques Vieira. V.11, n.3, 2012.

DOI: Em andamento. 
Tabela 1: Produção Científica apresentada nas seis revistas analisadas, nos últimos dez anos.

\begin{tabular}{lccccccccccc} 
Período/Revista & $\mathbf{2 0 0 4}$ & $\mathbf{2 0 0 5}$ & $\mathbf{2 0 0 6}$ & $\mathbf{2 0 0 7}$ & $\mathbf{2 0 0 8}$ & $\mathbf{2 0 0 9}$ & $\mathbf{2 0 1 0}$ & $\mathbf{2 0 1 1}$ & $\mathbf{2 0 1 2}$ & $\mathbf{2 0 1 3}$ & Total \\
\hline C \& E & 40 & 36 & 24 & 28 & 36 & 39 & 45 & 60 & 60 & 60 & 428 \\
EENCl & - & - & 18 & 18 & 18 & 24 & 36 & 36 & 21 & 32 & 203 \\
IENCl & 13 & 17 & 18 & 18 & 18 & 20 & 24 & 24 & 36 & 35 & 223 \\
REEC & 23 & 21 & 22 & 30 & 40 & 58 & 96 & 29 & 33 & 27 & 379 \\
RBPEC & 24 & 15 & 12 & 12 & 18 & 20 & 22 & 30 & 30 & 29 & 212 \\
Alexandria & - & - & - & - & 18 & 22 & 14 & 21 & 30 & 33 & 138 \\
Total & $\mathbf{1 0 0}$ & $\mathbf{8 9}$ & $\mathbf{9 4}$ & $\mathbf{1 0 6}$ & $\mathbf{1 4 8}$ & $\mathbf{1 8 3}$ & $\mathbf{2 3 7}$ & $\mathbf{2 0 0}$ & $\mathbf{2 1 0}$ & $\mathbf{2 1 6}$ & $\mathbf{1 5 8 3}$
\end{tabular}

A Tabela 1 traz um breve panorama da produção científica aprovada e publicada nas revistas ao logo desses dez anos. Observa-se que, dentre as seis revistas analisadas, a que possui maior produção de artigos publicados é a Revista Ciência \& Educação, um total de (27,03\%), em segunda colocação a Revista Electrónica de Enseñanza de las Ciencias $(23,94 \%)$, seguida pelas demais revistas: Revista Investigação em Ensino de ciências (14,08\%), Revista Brasileira de Pesquisa em Educação em Ciências (13,39), Revista Experiências em Ensino de Ciência (12,82\%), Revista de Educação Ciência e Tecnologia (8,71\%).

Dessa forma, considerando-se a relação dessas revistas com a temática FP nas SI, pode-se verificar os seguintes resultados: Ciência \& Educação $(0,70 \%)$ da sua produção, nos últimos dez anos, são referentes a temática analisada, seguido por EENCI (1,98\%), IENCI (1,34\%), REEC (0,26\%), RBPEC (0,94\%) e ALEXANDRIA (0\%). Analisando essa produção, a Revista EENCI possui a liderança, por ter dois artigos dentre o total de artigos publicados na área durante os últimos dez anos. Índices considerados discrepantes, quando comparados com a totalidade de artigos produzidos no período analisado. É importante também destacar que os periódicos EENCl e ALEXANDRIA não possuem publicação durante os dez anos analisados na pesquisa, devido às publicações iniciais nessas revistas serem inferior ao período analisado, a EENCl obteve sua primeira publicação em 2005 e a ALEXANDRIA em 2008.

\section{Os Grupos Formadores: Como a Formação de Professores é Estruturada nos Artigos?}

Existem diversas formas e métodos para os grupos de FC serem estruturados, a mais eficaz está relacionada com os objetivos, espaços e contextos específicos de cada grupo 
formador. A Tabela 2 oferece um breve panorama de quatro entre os onze artigos identificados nos periódicos analisados, referente à Formação de Professores nas séries Iniciais.

O artigo intitulado Ensino de Ciências no Fundamental 1: Perfil de um grupo de professores em Formação Continuada num contexto de Alfabetização Científica (NIGRO; AZEVEDO, 2011), publicado na Revista Ciência \& educação, com o objetivo de promover a Alfabetização Científica, apresentou e analisou parte do perfil de 24 professores envolvidos, que atuavam do 1 o ao 5o ano do Ensino Fundamental I. Durante o ano de 2004, em duas escolas da rede municipal de ensino de São Paulo, onde as mesmas promoviam uma parada mensal das atividades para receber e trabalhar com o profissional formador, além de este acompanhar os trabalhos realizados em sala de aula, ao longo do mês. Como forma de obtenção de dados, inicialmente, utilizou-se um questionário, o qual objetivava traçar um perfil parcial dos professores sujeitos dessa pesquisa, posteriormente, os professores foram convocados, voluntariamente, a se apresentarem para participarem de entrevistas semiestruturadas, que pretendiam esclarecer algumas das respostas apresentadas pelos mesmos, no questionário. Estas entrevistas foram gravadas simultaneamente por quatro pesquisadores (todos alunos de pósgraduação na época) e duraram, aproximadamente, quarenta e cinco minutos. Por fim, após o encerramento das entrevistas, houve um debate entre os quatro pesquisadores, a fim de possibilitar a triangulação dos dados.

O artigo intitulado O Conhecimento Físico na Formação de Professores do Ensino Fundamental I (ABREU; BEJARANO; HOHENFELD, 2013), analisou a influência de estratégias formativas baseadas na resolução de problemas relativos ao conhecimento físico na aprendizagem dos professores. A presente pesquisa utilizou como estratégia de conhecimento e método de investigação a pesquisa-ação, a fim de trabalhar com e não sobre os professores. A formação foi dividida em três etapas: A primeira visou a apresentar as características de um ensino de Ciências baseado na investigação, utilizando vídeos sobre o ensino dessa disciplina e discussões de textos; a segunda etapa consistiu no desenvolvimento de seis atividades do conhecimento físico, conforme proposto por Carvalho et al. (1998); na última etapa, discutiram os resultados das atividades desenvolvidas por duas professoras em suas classes, utilizando as filmagens como referência. Dessa forma, como objeto de coleta utilizou-se os registros elaborados pelas professoras, após a participação na atividade do conhecimento físico, o qual teve como foco discutir o Ensino de Ciências na perspectiva da investigação, do diário da pesquisadora, de filmagens realizadas durante o desenvolvimento das atividades por duas professoras em suas salas e dos e-mails trocados entre professoras e pesquisadores.

O artigo intitulado Formação Continuada de professores das Séries Iniciais na Modalidade semi-presencial: aprendendo Ciências com atividades Mãos-na-massa (SCHROEDER; VEIT; BARROSO, 2011), foi oferecido como um curso de extensão da UFRGS, tendo como objetivo a formação de tutores para atuarem em futuros cursos de formação continuada de professores, na

DOI: Em andamento. 
modalidade EAD, promovidos pelo LMIC da UFRJ. Ocorreu durante dois meses, possuindo um total de $40 \mathrm{~h}$-aula, sendo $50 \%$ desse total presencial e $50 \%$ à distância. Os sujeitos envolvidos na pesquisa foram apresentados ao Teleduc (2010), usado como plataforma virtual. Foi composto por duas turmas, possuindo um total de 77 alunos-professores que iniciaram o curso, 37 concluíram a parte presencial e 29 deles concluíram todo o curso. A ementa do curso incluiu, no que diz respeito ao ensino-aprendizagem de Física: a introdução ao aprendizado mãos-na-massa; maneiras de enfocar a Física para crianças com idades entre sete e dez anos; estratégias para introduzir as práticas de ensino propostas; formas de avaliação destas atividades; atividades mãos-na-massa de Física para as quatro séries iniciais do Ensino Fundamental: A natureza da ciência, Aulas mãos-na-massa, Calor e temperatura, A água e o ar, Ímãs, Eletricidade, Os estados da matéria, Forças e máquinas, Pressão e empuxo, e Unidades e instrumentos de medida. E em relação ao ensino-aprendizagem a distância: conceitos básicos de ambiente virtual de aprendizagem e seu uso; o papel do professor e do aluno em cursos a distância (organização do estudo, disciplina e autonomia). Como forma de coleta de dados os pesquisadores utilizaram durante ou ao final da aula presencial, era exigida dos alunos-professores a elaboração de um relatório de algumas das atividades realizadas, os relatórios corrigidos, entregue na aula subsequente, serviram como elemento da avaliação formativa. A avaliação dos alunosprofessores relativa à parte presencial foi calcada nas observações realizadas durante o desenvolvimento das atividades e em tais relatórios, enquanto as atividades a distância, estas aconteciam, mas especialmente após a conclusão da parte presencial, o ambiente virtual foi utilizado para debate de ideias e compartilhamento de experiências, postagem das tarefas solicitadas nos portfólios individuais e troca de mensagens eletrônicas dos participantes entre si e destes com os professores.

O artigo intitulado A Formação de Futuros Professores dos Anos Iniciais do Ensino Fundamental: uma discussão a partir de uma atividade de ensino de geometria (POZEBON; LOPES; FRAGA ; HUNDERTMARCK, 2008), objetiva discutir sobre a formação inicial de professores que ensinam matemática nos anos iniciais do Ensino Fundamental a partir da organização e do desenvolvimento de uma atividade de ensino de geometria num grupo que tem a participação de professores universitários, professores de Educação Básica e estudantes dos cursos de Licenciatura em Pedagogia e em Matemática, denominado Grupo de Estudos e Pesquisas em Educação Matemática (GEPEMat), estas atividades são construídas por essa equipe juntamente com a Pós-graduação em Educação e professores universitários e da rede pública e são desenvolvidas no Clube de Matemática - CluMat em quatro escolas da rede pública estadual de Santa Maria. As reflexões apresentadas neste artigo são baseadas nas ações desenvolvidas pelo GEPEMat, e aplicadas pelo CluMat, pautada nos princípios da Atividade Orientadora de Ensino, sendo estes coletados através de relatos orais nas reuniões do grupo com os sujeitos da pesquisa, composto por quatro estudantes do curso de Licenciatura em Pedagogia e um do curso de 
Licenciatura em Matemática. Também foram usados relatórios escritos, fotografias e gravações em vídeo feitas nas escolas em que a atividade foi desenvolvida.

Tabela 2: Características gerais dos artigos analisados referentes

à Formação de Professores das SI.

\begin{tabular}{|c|c|c|}
\hline TíTULO & OBJETIVO & $\begin{array}{l}\text { CARACTERÍSTICAS } \\
\text { DA FORMAÇÃO }\end{array}$ \\
\hline $\begin{array}{l}\text { Ensino de Ciências no } \\
\text { Fundamental 1: Perfil de um } \\
\text { grupo de professores em } \\
\text { Formação Continuada num } \\
\text { contexto de Alfabetização } \\
\text { Científica. Rogério } \\
\text { Gonçalves Nigro e Maria } \\
\text { Nizete Azevedo. }\end{array}$ & $\begin{array}{l}\text { Promover a Alfabetização } \\
\text { Científica. }\end{array}$ & $\begin{array}{l}\text { Grupo com } 24 \text { professores } \\
\text { participantes, no período de } \\
\text { um ano. }\end{array}$ \\
\hline $\begin{array}{l}\text { O Conhecimento Físico na } \\
\text { Formação de Professores do } \\
\text { Ensino Fundamental I. Lenir } \\
\text { Abreu, Nelson Bejarano e } \\
\text { Dielson Hohenfeld. }\end{array}$ & $\begin{array}{l}\text { Analisar a influência de } \\
\text { estratégias formativas } \\
\text { baseadas na resolução de } \\
\text { problemas relativos ao } \\
\text { conhecimento físico na } \\
\text { aprendizagem dos } \\
\text { professores. }\end{array}$ & $\begin{array}{l}\text { Grupo composto por treze } \\
\text { professores, os quais } \\
\text { desenvolviam as atividades em } \\
\text { quarenta horas presenciais e } \\
\text { quarenta horas não } \\
\text { presenciais (planejamento, } \\
\text { leituras e registros reflexivos). }\end{array}$ \\
\hline $\begin{array}{l}\text { A Formação de Futuros } \\
\text { Professores dos Anos } \\
\text { Iniciais do Ensino } \\
\text { Fundamental: uma } \\
\text { discussão a partir de uma } \\
\text { atividade de ensino de } \\
\text { geometria. Simone } \\
\text { Pozebon, Anemari Roesler } \\
\text { Luersen Vieira Lopes, Laura } \\
\text { Pippi Fraga e Jucilene } \\
\text { Hundertmarck. }\end{array}$ & $\begin{array}{l}\text { Discutir sobre a formação } \\
\text { inicial de professores que } \\
\text { ensinam matemática nos } \\
\text { anos iniciais do EF a partir da } \\
\text { organização e do } \\
\text { desenvolvimento de uma } \\
\text { atividade de ensino de } \\
\text { geometria. }\end{array}$ & $\begin{array}{l}\text { Grupo composto por } \\
\text { professores universitários, } \\
\text { professores de Educação } \\
\text { Básica e estudantes dos cursos } \\
\text { de Licenciatura em Pedagogia } \\
\text { e em Matemática. }\end{array}$ \\
\hline $\begin{array}{l}\text { Formação Continuada de } \\
\text { professores das Séries } \\
\text { Iniciais na Modalidade semi- } \\
\text { presencial: aprendendo }\end{array}$ & $\begin{array}{l}\text { Formar tutores para } \\
\text { atuarem em futuros cursos } \\
\text { de formação continuada de } \\
\text { professores, na modalidade }\end{array}$ & $\begin{array}{l}\text { Grupo com } 77 \text { professores } \\
\text { participantes, ao longo de dois } \\
\text { meses. }\end{array}$ \\
\hline
\end{tabular}

R. B. E. C. T., vol 8, Ed. Sinect, jan-abr.2015 ISSN - 1982-873X

DOI: Em andamento. 
Ciências com atividades

Mãos-na-massa. Carlos

Schroeder, Eliane Angela

Veit e Marta Feijó Barroso.
EAD, promovidos pelo LMIC

da UFRJ.

\section{Considerações Finais}

A perspectiva com que foi realizado esse estudo visa, sobretudo, apresentar um panorama da área de trabalhos que envolvem a FP voltados para as SI do Ensino Fundamental I. O estudo constituiu-se na organização dos dados coletados em tabela e breve descrição de quatro dos onze artigos, para melhor visualizar sua leitura e análise. A partir das análises realizadas nos seis periódicos que divulgam trabalhos voltados para a área de Ensino de Ciências, pode-se observar que dentre os 1583 artigos publicados nos periódicos analisados, nos últimos dez anos, apenas 11 eram destinados à FP nas SI. Os resultados dos trabalhos aqui sumarizados reforçam as palavras de Teixeira e Megid Neto (2005), que existe realmente um déficit de trabalhos direcionado às SI, e que essa lacuna deve ser preenchida por trabalhos posteriores.

Logo, o presente mapeamento da produção dos seis periódicos analisados relativa aos últimos dez anos, representa valiosa contribuição, ao permitir visualizar características referentes à FP direcionada ao Ensino de Ciências nas SI. De forma que, por meio dos resultados obtidos, é possível perceber a necessidade de pesquisas direcionadas para as $\mathrm{SI}$, que contribua assim, para novas perspectivas e reflexões acerca do EC.

\section{Referências}

ABREU, L. BENJARANO, N. HOHENFELD, D. O Conhecimento Físico na Formação de Professores do Ensino Fundamental I. Revista Investigação em Ensino de Ciências. V1, n.1, 2013. Disponível em : < http://www.if.ufrgs.br/ienci/artigos/Artigo_ID318/v18_n1_a2013.pdf> Acesso em 04 Jul 2014.

AMARAL, I. A. do. Programas e Ações de Formação Docente em Educação Ambiental. In: TAGLIEBER, J.E. \& GUERRA, A.F.S. (Orgs.). Pesquisas em Educação Ambiental: Pensamentos e reflexões de pesquisadores em Educação Ambiental. Pelotas: Ed. Universitária/UFPEL, 2004. p. 145-167. Disponível em:< http://www.fe.unicamp.br/formar/pag_producao.htm> Acesso em 10 jul. 2014.

BARCELOS, N. N. S.; VILLANI, A. Troca entre universidade e escola na formação docente: uma experiência de formação inicial e continuada. Ciência \& Educação. V.12, n.1, pp. 73-97, 2006.

BRASIL, Orientações Curriculares para o Ensino Médio. Brasília- Ministério da Educação, Secretária da Educação Básica. V.1, 2006. 
CARVALHO, A. M. P.; GIL-PÉREZ, D. Formação de Professores de Ciências. 2. ed. São Paulo: Cortez, 1993.

DUCATTI-SILVA, K.C. A formação no curso de Pedagogia para o ensino de ciências nas séries iniciais. Dissertação de Mestrado, Programa de Pós-Graduação em Educação, Faculdade de Filosofia e Ciências, Universidade Estadual Paulista “Júlio de Mesquita Filho", Marília, SP. 2005.

ECHEVERRÍA, R.A.; BELISÁRIO, C.M. Formação Inicial e Continuada de Professores Num Núcleo de Pesquisa em Ensino de Ciências. Rev. Brasileira de Pesquisa em Educação em Ciências. V.8, n.3, 2008.

FAGUNDES, S.M.K.; LIMA, V.M.R. Reconstruindo o ensino de Ciências nas séries iniciais por meio da Educação Continuada dos professores. Revista do Centro de Educação. V.34, n.2, pp. 359-371, maio 2009,.

FERNANDES, R. C. A.; MEGID NETO, J. Pesquisas sobre o estado da arte em educação em ciências: uma revisão em periódicos científicos brasileiros. Anais... Encontro Nacional de Pesquisa em Educação em Ciências, 6., Florianópolis, 2007.

FRACALANZA, H. O que sabemos sobre os livros didáticos para o ensino de ciências no Brasil. Campinas: Faculdade de Educação, Universidade Estadual de Campinas, 1992. 302p. (Tese de doutorado).

FRANCISCO, C. A.; QUEIROZ, S. L. A produção do conhecimento sobre o ensino de Química nas Reuniões Anuais da Sociedade Brasileira de Química. Química Nova, São Paulo, v. 31, n. 8, p. 2100-2110, 2008.

FREITAS, D.; VILLANI, A. Formação de professores de Ciências: um desafio sem limites. Investigações em Ensino de Ciências, v. 7, n. 3, pp. 215-230, 2002.

FOUREZ, G. Crise no Ensino de Ciências? Revista Investigações em Ensino de Ciências. V.8, n.2, pp.109-123, 2003. Disponível em: <www.if.ufrgs.br/public/ensino/v8/n2>. Acesso em 10 Jun.2014. Acesso em: 27 Jun 2014.

GARRIDO, E.A.R.; VILLAGRÁ, J.A.M.Las concepciones y creencias de profesores de ciencias naturales sobre ciencia, su enseñanza y aprendizaje, mediadas por la formación inicial, la educación continuada y la experiencia profesional. Revista Brasileira de Pesquisa em Educação em Ciências; v. 5, n. 2, 2005.

GARRIDO, E. \& CARVALHO, A. M. P. Discurso em sala de aula: uma mudança epistemológica e didática. In: Coletânea. 3a Escola de Verão. São Paulo, FEUSP, 1995.

KRASILCHIK, M. O professor e o currículo das ciências. São Paulo: EPU: Editora da Universidade de São Paulo, 1987, 80p.

DOI: Em andamento. 
LEMGRUBER, M. S. A Educação em Ciências Físicas e Biológicas a partir das Teses e Dissertações, de 1981 a 1995: uma História de sua História. Rio de Janeiro: UFRJ, 1999. (Tese de Doutorado). LIMA, M. C.A.B. Explique o que tem nessa história. São Paulo: USP, 2001. Tese (Doutorado em Educação).

LIMA, M.E.C.C.; MAUÉS, E. Uma releitura do papel da professora das séries iniciais no desenvolvimento e aprendizagem de ciências das crianças. Ensaio - Pesquisa em Educação em Ciências, Belo Horizonte, v.8, n. 2, p. 161-175, 2006.

LONGHINI, M. D. O CONHECIMENTO DO CONTEÚDO CIENTÍFICO E A FORMAÇÃO DO PROFESSOR DAS SÉRIES INICIAIS DO ENSINO FUNDAMENTAL. Investigações em Ensino de Ciências - V.13, n.2, pp.241-253, 2008.

MEGID NETO, J. (Coord.) O ensino de Ciências no Brasil - Catálogo analítico de teses e dissertações 1972-1995. Campinas (SP): FE/Unicamp e Grupo FORMAR Ciências/CEDOC, dezembro de 1998. Disponível em:<http://www.fe.unicamp.br/cedoc>. Acesso em: 27 jul. 2007.

MONTEIRO, M.A.A.;TEIXEIRA, O.P.B. O Ensino de Física nas Séries Iniciais do Ensino Fundamental: um estudo das influências das experiências docentes em sua prática em sala de aula. Investigações em Ensino de Ciências - V.9, n.1, pp. 7-25, 2004.

MOREIRA,M.A. Pesquisa básica em Educação em Ciências: uma visão pessoal. Revista Chilena de Educación Científica. V. 3, 2004..

NONO, M.A.; MIZUKAMI, M.G.N. Processos de formação de professoras iniciantes. Revista Brasileira de Estudos Pedagógicos, Brasília, v. 87, n. 217, p. 382-400, 2006.

MEJID NETO,J.; ROCHA, M. B. Práticas de Formação de Professores para o Ensino de Ciências nos anos iniciais do Ensino Fundamental: uma revisão da literatura. Ensino Em-Revista, Uberlândia, v.17, n.1, p. 155-176, jan./jun. 2010.

MENEZES, L. C. (Org.) Formação continuada de professores de ciências no contexto iberoamericano. Campinas, São Pulo: Autores Associados: NUPES, 1996 (Coleção formação de professores) $170 \mathrm{p}$.

NIGRO, R. G.; AZEVEDO, M. N. Ensino de ciências no fundamental 1: perfil de um grupo de professores em formação continuada num contexto de alfabetização científica. Ciência \& Educação: Bauru. V.17, n.3, pp. 705-720, 2011,.

PÉREZ, R.J.; AGUADO, A.M.W. ¿Es posible el cambio en los modelos didácticos personales?: Obstáculos en profesores de Ciencias Naturales de Educación Secundaria Revista Interuniversitaria de Formación de Profesorado, V.17, n.1 , pp. 113-131, 2003.

PIMENTA, S. G.; ANASTASIOU, L.G.C. Docência no ensino superior. São Paulo: Cortez, 2002. 
RODRIGUES, M.J.;VIEIRA, R.M. Programa de formação de educadoras de infância: Seu contributo para a (re)construção de conceções Ciência-Tecnologia-Sociedade. Revista Electrónica de Enseñanza de las Ciencias. V.11, n.3, 2012. Disponível em: < http://reec.uvigo.es/volumenes/volumen11/REEC_11_3_2_ex664.pdf> Acesso em: 06 Juj 2014.

TEIXEIRA, P. M. M.; MEGID NETO, J. Breve Panorama das investigações que incidem sobre o Ensino de Biologia no Brasil. Anais... V Encontro Nacional de Pesquisa em Educação em Ciências, 2005.

SILVA, N. S. O repertório de conhecimentos de um grupo de professores de ciências específicos ao ensino de química no nível fundamental. Dissertação de mestrado. Faculdade de Educação da UFMG, 2003.

SLONGO, I. I. P. A produção acadêmica em ensino de biologia: um estudo a partir de teses e dissertações. Centro de Ciências da Educação, UFSC, Florianópolis, 2004. (Tese de Doutorado) SCHNETZLER, R. P. Como associar ensino com pesquisa na formação inicial e continuada de professores de Ciências? Atas do II Encontro Regional de Ensino de Ciências. Piracicaba: UNIMEP, 18-20 out, 1996.

SCHÖN, D. El profesional reflexivo - cómo piensan los profesionales cuando actúan. Barcelona: Ediciones Paidós, 1998.

SCHROEDER, C.; VEIT, E.A.; Marta Feijó BARROSO, M.F. Formação Continuada de professores das Séries Iniciais na Modalidade semi-presencial: aprendendo Ciências com atividades Mãos-namassa. Experiências em Ensino de Ciências. V. 6, p.189-30, 2011.

SCHWARTZMAN, S."Pesquisa Universitária e Inovação no Brasil." in Avaliação de políticas de ciência, tecnologia e inovação: diálogo entre experiências internacionais e brasileiras, editado por Centro de Gestão e Estudos Estratégicos. Anais... Brasília: CGEE. 2008, pp. 19-43.

TENREIRO-VIEIRA, C.; VIEIRA, R. M. Construção de práticas didático-pedagógicas com orientação CTS:impacto de um programa de formação continuada de professores de ciências do ensino básico. Ciência \& Educação: Bauru. V.11, n.2, pp. 191-211, 2005.

VEIGA, I.P.A; VIANA, C.M.Q.Q. A escola mudou. Que mude a formação de professores! Cap. 1 Formação de professores: Um campo de Possibilidades Inovadoras. $3^{a}$ ed. Campinas, SP: Papirus, pp. 13-34, 2012.

VIECHENESKI, J.P.; CARLETTO, M.R. Ensino de Ciências e Alfabetização Científica nos anos iniciais do Ensino Fundamental: um olhar sobre as escolas públicas de Carambeí. Anais... VII Encontro de Pesquisa em Educação em Ciências 2012. 
Luiza Renata Felix de Carvalho Lima - Graduada em Licenciatura em Química - Universidade Estadual de Santa Cruz (UESC) e Mestranda do Programa de Pós-Graduação em Educação e Ensino de Ciências (PPGEC) da UESC - luiza_renata_felix@hotmail.com

Maria Elvira do Rego Barros Bello - Doutora em Ciências (com área de concentração em Físico-Química) - Universidade Federal de São Carlos (UFSCar), Docente do Departamento de Ciências Exatas e Tecnológicas (DCET) da Universidade Estadual de Santa Cruz (UESC). Professora do Programa de Pós-Graduação em Educação em Ciências (PPGEC) da UESC ebello99@yahoo.fr

Maxwell Roger da P. Siqueira - Doutor em Educação (com ênfase em Ensino de Física e Matemática) - Faculdade de Educação da USP (FEUSP), Docente do Departamento de Ciências Exatas e Tecnológicas (DCET) da Universidade Estadual de Santa Cruz (UESC). Professor do Programa de Pós-Graduação em Educação em Ensino de Ciências (PPGEC) da UESC - maxwell_siqueira@hotmail.com 